[Agr. Biol. Chem., Vol. 33, No. 7, p. 1013 1017, 1969\}

\title{
Micro Methods for Determination of 3-Ketosucrose and 3-Ketoglucose
}

\author{
By Sakuzo Fukui and Koichi Hayano \\ The Institute of Applied Microbiology, The University \\ of Tokyo, Tokyo, Japan \\ Received December 5, 1968
}

\begin{abstract}
Methods for differential determination of 3-ketosucrose and 3-ketoglucose were established. For determination of 3-ketosucrose, alkaline treatment with $0.1 \mathrm{~N} \mathrm{NaOH}$ was found to be most effective. In this method, 3-ketosucrose gave a characteristic absorption spectrum with a molar extinction coefficient of $6.3 \times 10^{3} \mathrm{M}^{-1} \mathrm{~cm}^{-1}$ at $340 \mathrm{~m} \mu$, while 3-ketoglucose did not show a significant absorption spectrum within a range from 300 to $400 \mathrm{~m} \mu$.

By mixing with $0.2 \mathrm{M}$ phosphate buffer, $\mathrm{pH} 7.0$, 3-ketoglucose gave a characteristic absorption spectrum with a molar extinction coefficient of $3.8 \times 10^{3} \mathrm{M}^{-1} \mathrm{~cm}^{-1}$ at $310 \mathrm{~m} \mu$, while 3-ketosucrose showed little absorbance.

From the reduction rate of 2,6-dichloroindophenol with 3-ketoglucose, the ketosugar was determined. 3-Ketosucrose was not able to reduce the reagent at all.

The methods established here were not affected by fructose.
\end{abstract}

Recently, 3-ketoglycosides have been proved to be the first intermediates in the metabolic pathway of carbohydrate by Agrobacterium tumefaciens, a plant tumor inducing bacterium. ${ }^{1-5}$ As one of their general properties, it was found that every 3-ketoglycoside so far isolated showed strong reducing power and could reduce readily cupric ion to cuprous form by the Somogyi-Nelson reagent at room temperature. On the basis of this finding, a new determination method for 3-ketosugar was reported in our previous paper. ${ }^{61}$ On the other hand, Feingold et $a l^{7}$ indicated the

1) S. Fukui, R. M. Hochster, R. Durbin, E. E. Grebner and D.S. Feingold, Bull. Res. Council Israel, 11A4, 262 (1963).

2) S. Fukui and R. M. Hobhster, Can. J. Biochem. Physiol., 41, 2363 (1963).

3) S. Fukui, Biochem. Biophys. Res. Commun., 18, 186 (1965).

4) K. Hayano and S. Fukui, J. Biochem. (Tokyo), 64, 901 (1968).

5) S. Fukui, J. Bacteriol., 97, Feb. issue (1969).

6 S. Fukui, A. Tai and R. M. Hochster, J. Gen. Appl. Microbiol. (Tokyo), 11, 75 (1965).

7) E. E. Grebner and D.S. Feingold, Biochem. Biophys. Res. Commun., 19, 37 (1965). possibility of 3-ketosucrose determination by alkaline treatment with $0.1 \mathrm{~N} \mathrm{NaOH}$. In the study of 3-ketosucrose-hydrolyzing enzyme, ${ }^{81}$ a novel enzyme named as $\alpha$-D-3-ketoglucosidase, differential determination methods for the substrate, 3-ketosucrose, and the product, 3 -ketoglucose, were required to establish the stoichiometry of the reaction.

In this paper, we describe new methods for 3-ketosucrose and 3-ketoglucose determinations.

\section{METHODS AND RESULTS}

\section{Determination of 3-ketosucrose}

For determination of 3-ketosucrose, the alkaline treatment was employed. By the treatment, 3-ketosucrose showed a characteristic absorption spectrum having a maximum at $340 \mathrm{~m} \mu^{9}$

8) K. Hayano and S. Fukui, Abstracts of the 41 th Meeting of Japanese Biochemical Society, Tokyo (1968) Abstracts C-43.

9) K. Hayano and S. Fukui, J. Biol. Chem., 242, 3665 (1967). 
Standard. Crystalline 3-ketosucrose $\left(\mathrm{C}_{12} \mathrm{H}_{20^{-}}\right.$ $\mathrm{O}_{11} \cdot 3 \mathrm{H}_{2} \mathrm{O}, \quad \alpha$-D-ribo-hexopyranosyl-3-ulose- $\beta$-Dfructofuranoside) was prepared as described in our previous paper. ${ }^{1}$ Freshly prepared $1.0 \times 10^{-3} \mathrm{~m} 3$-ketosucrose solution was used as a standard solution.

Reagent. $\quad 0.15 \mathrm{~N} \mathrm{NaOH}$ solution.

Procedure. To $1.0 \mathrm{ml}$ of a sample containing 0.05 to $0.4 \mu \mathrm{mole}$ of 3-ketosucrose was added $2.0 \mathrm{ml}$ of $0.15 \mathrm{~N} \mathrm{NaOH}$ solution. After standing for $3 \mathrm{~min}$ at room temperature, optical density at $340 \mathrm{~m} \mu$ was measured. The maximum intensity was obtained after $3 \mathrm{~min}$ treatment. Under these conditions, the sugar gave a molar extiction coefficient of $6.5 \times$ $10^{3} \mathrm{~m}^{-1} \mathrm{~cm}^{-1}$. Other 3-ketoglucosides so far isolated such as 3-ketotrehalose, 3-ketomaltose, 3-ketocellobiose and 3-ketoglucose 1-phosphate were also determined by this method, and their molar extinction coefficients were 6.2, $5.5,3.55$ and $3.85 \times 10^{3} \mathrm{~m}^{-1} \mathrm{~cm}^{-1}$ at $340 \mathrm{~m} \mu$, respectively. The hydrolyzate of 3-ketosucrose with yeast invertase, i.e., a mixture of equimolar amounts of 3-ketoglucose and fructose, showed little absorbance at a range from 325 to $400 \mathrm{~m} \mu$ as seen in Fig. 1. Fructose did

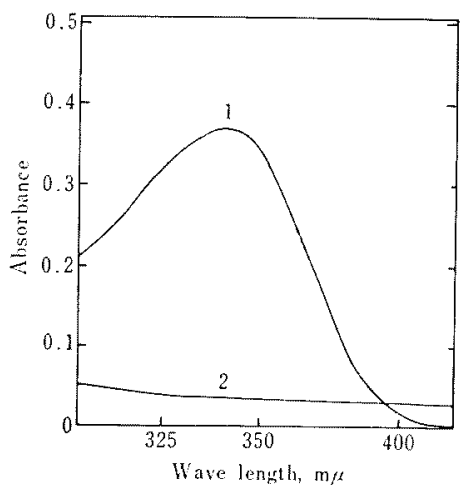

FIG. 1. Absorption Spectra of 3-Ketosucrose and 3Ketoglucose Measured in $0.1 \mathrm{~N} \mathrm{NaOH}$.

Curve 1, absorption spectrum of 3-ketosucrose (0.17 $\mu$ moles); curve 2 , absorption spectrum of 3 ketoglucose $(0.26 \mu$ moles $)$.

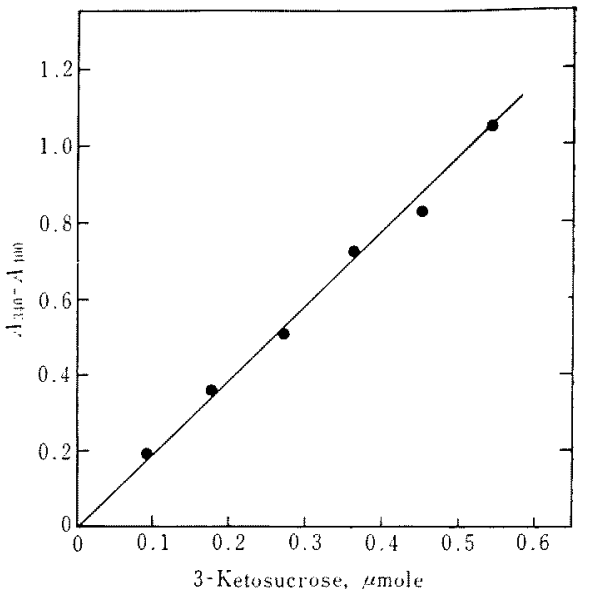

FIG. 2. Determination Curve for 3-Ketosucrose in Alkaline Treatment.

not show any absorbance at this range in $0.1 \mathrm{~N}$ $\mathrm{NaOH}$. When the sample contained both 3ketosucrose and 3-ketoglucose, the amount of 3-ketosucrose was determined by substracting the absorption value at $400 \mathrm{~m} \mu$ from that at $340 \mathrm{~m} \mu$, because 3-ketoglucose gave equal values at there two wavelengths. The determination curve is shown in Fig. 2.

\section{Determination of 3-ketoglucose}

Method A. 3-Ketoglucose solution in distilled water did not show any absorbance at a range from 260 to $400 \mathrm{~m} \mu$, but in the presence of a high concentration of phosphate buffer at a neutral $\mathrm{pH}$, the ketosugar have a characteristic absorption spectrum having a maximum at $310 \mathrm{~m} \mu$ (Fig. 3).

Standard. 3-Ketoglucose $\left(\mathrm{C}_{6} \mathrm{H}_{10} \mathrm{O}_{6} \cdot 1 / 2 \mathrm{H}_{2} \mathrm{O}\right.$, D-ribo-hexos-3-ulose) was isolated in a crystalline form in the previous paper. ${ }^{10}$ The compound was hygroscopic in atmosphere and was unstable in an aqueous solution, so that the hydrolyzate of 3-ketosucrose with yeast invertase was used as a standard solution of

10) S. Fukui and R. M. Hochster, J. Amer. Chem. Soc., 85. 1697 (1963). 


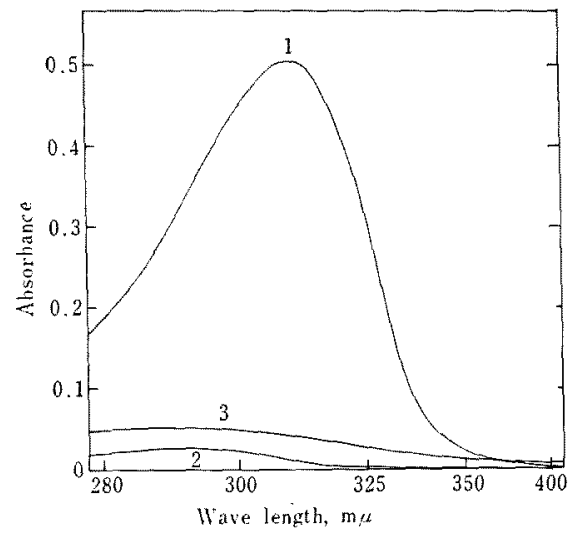

FIG. 3. Absorption Spectra of 3-Ketoglucose and 3Ketosucrose Measured in $0.2 \mathrm{M}$ Phosphate Ruffer, pH 7.0.

Curve 1, 3-ketoglucose $(0.26 \mu$ moles $)$; curve 2 , 3-ketosucrose $(0.17$ umoles); curve 3 , 3-ketoglucose $(0.26 \mu$ moles $)$ in $0.1 \mathrm{M}$ phosphate buffer, $\mathrm{pH} 6.0$.

3-ketoglucose in this paper. To $1.0 \mathrm{ml}$ of $10 \times$ $10^{-3} \mathrm{M}$ 3-ketosucrose solution in distilled water was added $10 \mu \mathrm{g}$ of yeast invertase (Grade VI, Sigma Chem. Co.). Complete hydrolysis of 3-ketosucrose took place during the treatment with the invertase for $5 \mathrm{~min}$ at room temperature without addition of a buffer. The hydrolyzate thus obtained was used as a standard solution of 3-ketoglucose. The ketosugar is so unstable that the standard solution should be freshly prepared.

Reagent. $\quad 1.0 \mathrm{M}$ phosphate buffer, $\mathrm{pH} 7.0$.

Procedure. To $1.6 \mathrm{ml}$ of a sample containing 0.05 to $0.4 \mu \mathrm{mole}$ of 3 -ketoglucose was added $0.4 \mathrm{ml}$ of the phosphate buffer and mixed. The mixture was allowed to stand for $3 \mathrm{~min}$ at room temperature, and then optical density at $310 \mathrm{~m} \mu$ was measured against a reagent blank. The intensity reached maximum after $3 \mathrm{~min}$ standing (Fig. 4). Fructose did not show any absorbance at $310 \mathrm{~m} u$ in this method. Under these assay conditions, 3-ketoglucose gave a molar extinction coefficient of $3.8 \times 10^{3} \mathrm{~m}^{-1} \mathrm{~cm}^{-1}$, whereas 3-ketodi-

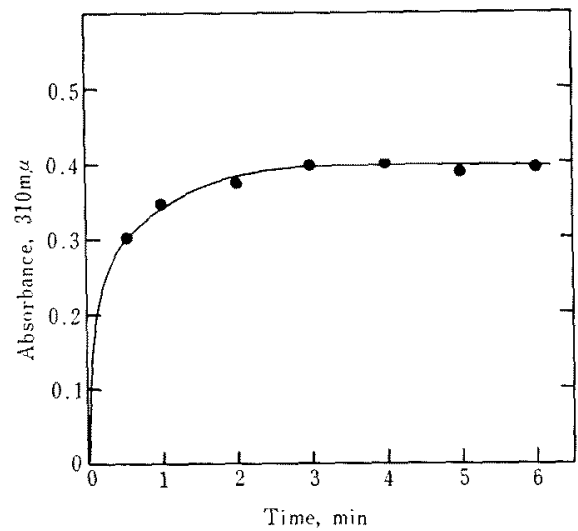

FIG. 4. Time Course of Intensity Change in Absorbance at $310 \mathrm{~m} \mu$ in Method A (3-ketoglucose, $0.21 \mu$ moles).

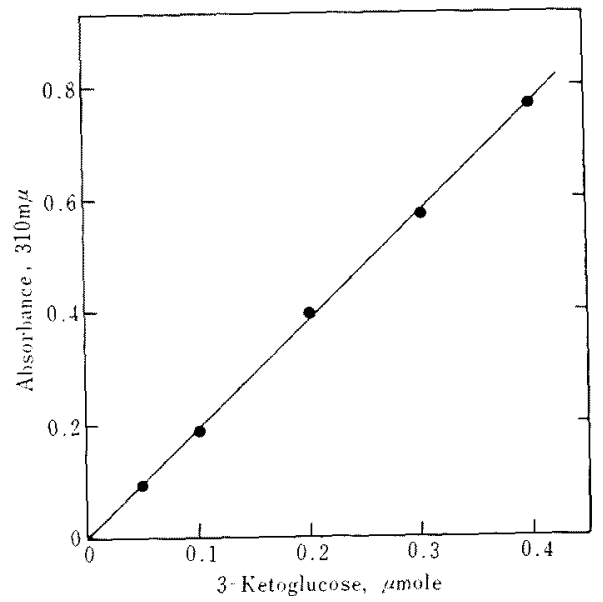

FIG. 5. Determination Curve for 3-Ketoglucose in Method A.

saccharides such as 3-ketosucrose, 3-ketotrehalose, 3-ketomaltose and 3-ketolactose showed no absorbance at $310 \mathrm{~m} \mu$. The optical density depended on both concentration and $\mathrm{pH}$ of the phosphate buffer used. The maximum value of intensity was obtained in $0.1 \mathrm{~m}$ or higher concentration (final concentration) of phosphate buffer at $\mathrm{pH}$ 7.0. The determina- 
tion curve is shown in Fig. 5. Completely same curve was obtained with crystalline 3ketoglucose as standard.

Method $B$. When 3-ketoglucose was incubated with 2,6-dichloroindophenol in a phosphate buffer, $\mathrm{pH} 7.0$, at room temperature, obvious reduction of the color was observed, while 3-ketosucrose showed little. reducing power under these conditions. By applying this finding, the following two procedures were developed for the determination of 3-ketoglucose.

Standard. Same as in Method A.

Reagents. (i), $3 \times 10^{-4} \mathrm{M}$ 2,6-dichloroindophenol solution.

(ii), 1.0 м phosphate buffer, $\mathrm{pH} 7.0$.

Procedure 1. To a mixture of $0.5 \mathrm{ml}$ of the 2, 6-dichloroindophenol solution, $0.3 \mathrm{ml}$ of the phosphate buffer and $1.2 \mathrm{ml}$ of distilled water

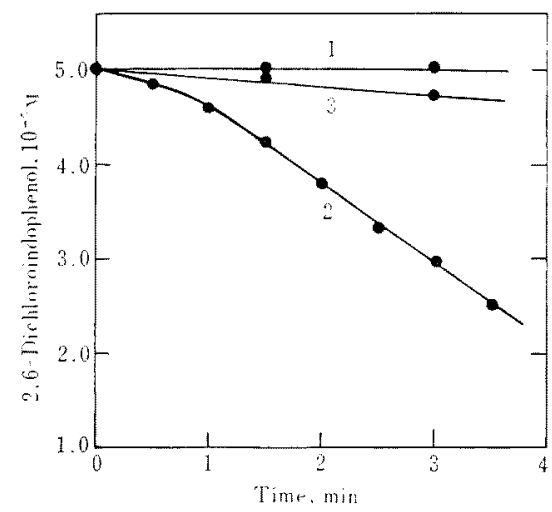

FIG. 6. Reduction of 2,6-Dichloroindophenol with 3-Ketoglucose in Method B (Procedure 1).

Curve 1, 3-ketosucrose (1.0 /mole) in $0.1 \mathrm{~m}$ phosphate buffer, $\mathrm{pH} 7.0$; curve 2, 3-ketoglucose (1.0 4 mole) in $0.1 \mathrm{M}$ phosphate buffer, $\mathrm{pH} 7.0$; curve 3,3 -ketoglucose $(1.0$ pmole) in $0.1 \mathrm{M}$ phosphate buffer, pH 5.6. Molar extinction coefficients of 2,6-dichloroindophenol were $19.1 \%$ $10^{3} \mathrm{M}^{-1} \mathrm{~cm}^{-1}$ at $\mathrm{pH} 7.0$ and $9.5 \times 10^{3} \mathrm{M}^{-1} \mathrm{~cm}^{-1}$ at $\mathrm{pH}$ $5.6(9)$.

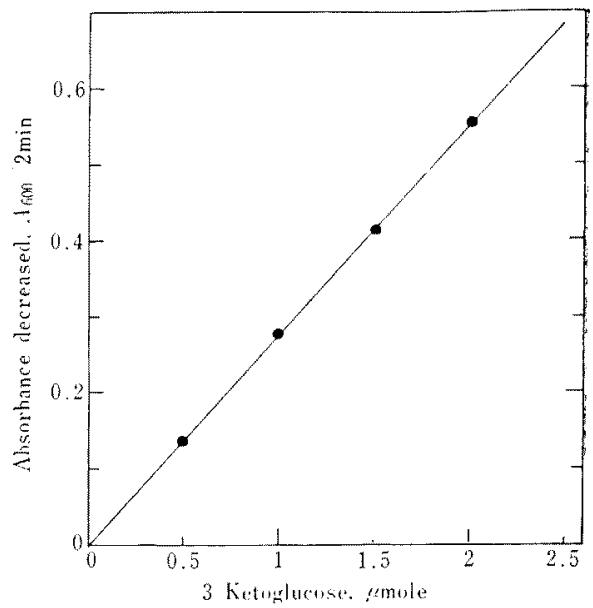

FIG. 7. Determination Curve for 3-Ketoglucose in Method B (procedure 1).

was added $1.0 \mathrm{ml}$ of a sample solution containing 0.5 to $2.0 \mu$ moles of 3 -ketoglucose, and mixed. Color reduction at $600 \mathrm{~m} \mu$ was followed with a spectrophotometer for $5 \mathrm{~min}$ at $20^{\circ}$. As seen with in Figs. 6 and 7 , after a lag period of approximately one minute, color reduction proceeded linearly and the rate was directly proportional to the amount of 3-ketoglucose. When $0.1 \mathrm{~m}$ phosphate buffer (final concentration) of $\mathrm{pH} 5.6$ was used in place of the phosphate buffer of $\mathrm{pH} 7.0$, only a little reduction of color was observed. The determination curve in this procedure is shown in Fig. 7.

Procedure 2. To $1.6 \mathrm{ml}$ of a sample containing 0.4 to $2.0 \mu$ moles of 3 -ketoglucose was added $0.2 \mathrm{ml}$ of the phosphate buffer, $\mathrm{pH} 7.0$, and mixed. After standing for $3 \mathrm{~min}$ at room temperature, $0.2 \mathrm{ml}$ of the 2,6-dichloroindophenol solution was added to the mixture, then the change in color intensity of the mixture at $600 \mathrm{~m} \mu$ was followed with a spectrophotometer for $5 \mathrm{~min}$ at room temperature (Fig. 8). The decrease in color intensity during the initial two minutes of the reaction was proportional to the amount of 3-keto- 


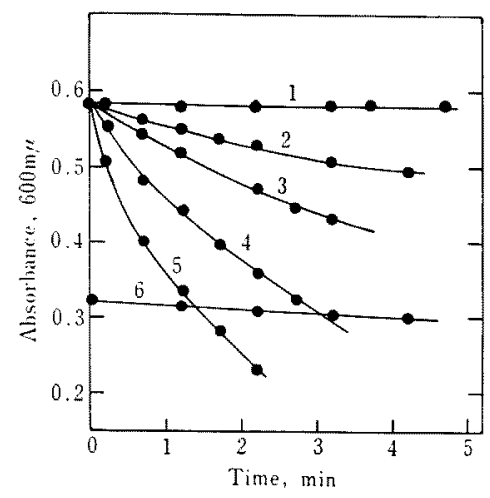

FIG. 8. Reduction of 2,6-Dichloroindophenol with 3-Ketoglucose in Method B (procedure 2).

Curve 1, without 3-ketoglucose; curves 2, 3, 4, and 5 are 3 -ketoglucose $0.33,0.67,1.33$ and 2.00 $\mu$ moles in $0.1 \mathrm{M}$ phosphate buffer, $\mathrm{pH} 7.0$, respectively; curve 6 , 3-ketoglucose, $1.33 \mu$ moles, in $0.1 \mathrm{M}$ phosphate buffer, $\mathrm{pH} 6.0$.

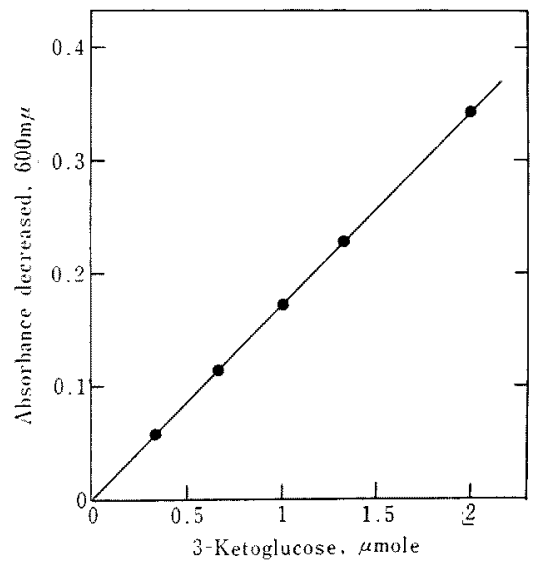

FIG. 9. Determination Curve for 3-Ketoglucose in Method B (procedure 2).

glucose. The determination curve is shown in Fig. 9.

\section{DISCUSSION}

3-Ketosucrose could be differentially deter- mined by alkaline treatment in the presence of 3-ketoglucose. In the treatment, 3-ketoglucose also gave some absorbance at $340 \mathrm{~m} \mu$, but the absorption disappeared within one minute after addition of the alkali solution. This might be due to the instability of 3ketoglucose in an alkaline solution. When the treatment was performed with $0.01 \mathrm{~N}$ $\mathrm{NaOH}$ (final concentration), 3-ketosucrose showed the same absorption spectrum as that in $0.1 \mathrm{~N} \mathrm{NaOH}$, but the rate of decrease in the absorbance at $340 \mathrm{~m} \mu$ given by 3-ketoglucose was very low.

Okazaki et al. ${ }^{11 \prime}$ reported that thymidinediphosphate 4-keto-6-deoxyglucose and 4-keto-6deoxyglucose 1-phosphate in $0.1 \mathrm{~N} \mathrm{NaOH}$ gave characteristic absorption spectra having maxima at 318 and $334 \mathrm{~m} \mu$, respectively. So, it should be stated that differential determination methods for 3-ketoglycoside and 4-ketoglycoside are not yet established.

Under the assay conditions in the alkaline treatment, L-ascorbic acid which has a chemical structure similar to that of 3-ketoglucose showed a little absorbance at $340 \mathrm{~m} \mu$, while in Method $B$ the acid strongly interfered the determination of 3-ketoglucose because of the high reducing power of the acid toward 2,6dichloroindophenol. When 10 or more $\mathrm{m} \mu$ moles of ascorbic acid was included in a sample, Method B could not be employed. In Method A, determination of 3-ketoglucose was not interfered even in the presence of $1 \mu$ mole of ascorbic acid.

In the procedure 1 of Method B, there was a lag period before the appearance of a linear decrease in color reduction, while there was no lag in the procedure 2 of Method B. This observation may indicate that 3 -ketoglucose is converted to a form having an ability to reduce 2,6-dichloroindophenol by the treatment with $0.02 \mathrm{~m}$ phosphate buffer, $\mathrm{pH}$ 7.0.

11) R. Okazaki, T. Okazaki, J. L. Strominger and A. M. Michelson, J. Biol. Chem., 237, 3014 (1962). 